\title{
Coupling signals between the osteoclast and osteoblast: how are messages transmitted between these temporary visitors to the bone surface?
}

\author{
Natalie A. Sims* and T. John Martin \\ Department of Medicine, St. Vincent's Institute of Medical Research, St. Vincent's Hospital, The University of Melbourne, Fitzroy, VIC, Australia \\ *Correspondence: nsims@svi.edu.au \\ Edited by: \\ Phil Salmon, Bruker-microCT, Belgium \\ Reviewed by: \\ Florent Elefteriou, Vanderbilt University, USA \\ Jan Tuckermann, Leibniz Institute for Age Research - Fritz Lipmann Institute, Germany
}

Keywords: osteoblast, osteoclast, coupling, osteocyte

Skeletal mass is regulated by two key activities: bone removal (resorption) by hematopoietic lineage osteoclasts and bone matrix formation by mesenchymal lineage osteoblasts. During adult life, these activities occur sequentially on the same surface: a process termed as remodeling. Tiny packets of bone are removed by osteoclasts and replaced by new bone matrix produced by osteoblasts. This continual renewal process allows repair of mechanical imperfections and calcium homeostasis.

The group of cells responsible for remodeling is termed as the basic multicellular unit (BMU) (1). To maintain bone mass at the same level during adulthood, the bone formed in each BMU must replace precisely the amount removed by resorption within that BMU. This stimulation of osteoblast activity in response to resorption is termed "coupling" (2), and it has long been of interest to understand how these two distinct cell types, on the same bone surface but at different times, could be linked so their activities are equal. The BMU and coupling concepts originally included only osteoclasts and osteoblasts, but over recent years, as more cellular contributors to remodeling have been identified (such as T-cells, macrophages, osteocytes, and precursor populations of osteoblasts and osteoclasts), the number of cells in the BMU has expanded (3-5). So too, more signaling pathways within the BMU have been identified $(6,7)$. All these signals converge on two cell types: the osteoclast and osteoblast, for only those cells are able of bone resorption and bone formation, respectively.
Osteoclasts and osteoblasts are not present on the bone surface simultaneously; the BMU exists, in different forms, at the same location over approximately 6 months in human bone. Early studies using undecalcified bone histology and timed fluorochrome labeling identified that bone resorption in iliac crest trabecular BMUs of adult human bone takes approximately 3 weeks (8), the formation response 3-4 months (9), and between the two activities there is a poorly understood "reversal phase" (10) of approximately 5 weeks (8). In rodents, the duration of this sequence is compressed, but a time delay between resorption and formation still exists: in rat alveolar bone, the reversal phase lasts for approximately 3.5 days (11). These numbers vary also with site, skeletal health, and treatment (12) and in some conditions, including osteoporosis there is an increased duration, or even arrest, of the reversal phase $(13,14)$. This review will explore mechanisms by which coupling signals may overcome the time delay between bone resorption and bone formation.

\section{THE MAIN CLASSES OF COUPLING FACTORS}

There are four main classes of osteoclastderived signals that may promote bone formation in the BMU: (1) matrix-derived signals released during bone resorption, (2) factors synthesized and secreted by the mature osteoclast, (3) factors expressed on the osteoclast cell membrane, and (4) topographical changes effected by the osteoclast on the bone surface. We have reviewed these different proposed signals extensively elsewhere $(6,7)$, but will here focus on how each type of signal might influence bone formation after the reversal phase. As it has been noted in economics, there tends to be a proliferation of putative factors that determine process outcomes until they resemble a "zoo of factors," with only a proportion of them being reliably reproduced in later research $(15,16)$. Since many coupling factors have only been identified in the past 10 years, most require validation by independent groups of researchers, working in multiple systems. This is particularly true of those factors identified in co-culture studies that disregard the time delay between bone resorption and formation.

\section{MATRIX-DERIVED FACTORS}

The bone matrix contains a store of latent growth factors, including transforming growth factor $\beta$ (TGF- $\beta$ ), bone morphogenetic protein 2 (BMP-2), plateletderived growth factor (PDGF), and the insulin-like growth factors (IGFs) (1721). All are deposited by osteoblasts during matrix production then released by osteoclastic activity on the bone surface (20), as well as via plasminogen activators $(22,23)$ and matrix-metalloproteinases (24). These factors, once released from the matrix, are unlikely to remain within the bone microenvironment for some 58 weeks during the reversal phase until they can influence mature osteoblasts upon their arrival at the bone surface. Rather, their main influences would be to stimulate osteoblast progenitors, including their 
recruitment (25-27), migration (26, 28$30)$, and differentiation $(29,31,32)$.

\section{OSTEOCLAST-SECRETED FACTORS}

Osteoclasts also secrete products to promote osteoblast precursor recruitment and differentiation and thereby promote bone formation in the BMU (3). Many such "osteoclast-derived coupling factors" have been identified, and some were validated by studies of genetically altered mice: cardiotrophin-1 (33), sphingosine1-phosphate, Wnt 10b, BMP-6 (34), CTHRC1 (35), and complement factor $3 \mathrm{a}$ (C3a) (36). We have described each of these in detail elsewhere (7); importantly, none are produced exclusively by osteoclasts, and many are also produced by other cell types in the vicinity of the BMU. Both active and inactive osteoclasts produce osteoclast-derived coupling factors (37). This concept is clinically important, since anti-resorptive inhibitors of osteoclast activity rather than osteoclast generation, such as cathepsin $\mathrm{K}$ inhibitors, may reduce bone resorption without blocking bone formation, leading potentially to an anabolic effect (38). Considering the time delay between bone resorption and formation, these factors cannot be expected to exist in a stable form at the BMU throughout the reversal phase. These factors stimulate not only the differentiated osteoblast but also, in the case of sphingosine-1phosphate and cardiotrophin-1, stimulate precursor commitment to the osteoblast lineage $(33,34)$.

\section{OSTEOCLAST MEMBRANE-BOUND FACTORS}

It has also been suggested that osteoclasts interact directly via cell surface regulatory proteins with mature osteoblasts to promote their activity. Factors proposed to act in this cell contact-dependent manner include EphrinB2 (39) and Semaphorin D (40). While plausible in vitro such cell contact-dependent mechanisms are problematic at the BMU because osteoclasts and osteoblasts are rarely in direct contact during remodeling. If such mechanisms occur, they may exist between osteoclasts and osteoblast precursors in the bone marrow space, or between osteoclasts and osteoblast-lineage cells in the remodeling canopy $(41,42)$, an anatomical structure observed above the BMU in human samples (43).

\section{WHICH CELL TYPE RESPONDS TO THESE OSTEOCLAST-DERIVED MESSAGES? \\ OSTEOBLAST PRECURSORS}

Whether matrix-released, osteoclastsecreted, or membrane-bound, the osteoblast precursor seems a more likely target for coupling factors than the mature osteoblast. Indeed, mouse genetic experiments indicate that active TGF- $\beta$ release during bone resorption induces osteoblast precursor migration to prior resorptive sites (29), thus making them available within the BMU for additional differentiation-promoting signals, such as matrix-derived IGF-1 (27). Osteoblast differentiation would be determined by these subsequent events, which are not well understood and may originate from a wide range of cells near the remodeling surface, including macrophages, T-cells, or the vasculature [reviewed in Ref. (7)]. Indeed, osteoclast-derived coupling factors are released by these other cell populations. For example, TGF- $\beta$, Semaphorin $4 \mathrm{D}, \mathrm{Wnt} 10 \mathrm{~b}$, and BMP-2 are released by T-cells (44-46) and macrophages $(47,48)$, while sphingosine-1-phosphate and PDGF are released by endothelial cells $(49,50)$. Nevertheless, the delay between osteoclastor matrix-derived coupling factor release and the arrival of osteoblasts on the bone surface (5-8 weeks) is much longer than the time required for osteoblasts to differentiate in vitro. Murine stromal cell lines in vitro require only 7 days before alkaline phosphatase production commences (51) and $<21$ days until they express the genes associated with a matrix-embedded osteocyte $(52,53)$. Recent lineage tracing experiments suggest the process is even faster in vivo, with only 6 days passing before $\alpha$-SMA precursors are incorporate into the bone matrix as osteocytes (54).

Osteoblast precursors, without the aid of any accessory cell, also sense the size and shape of pits formed by osteoclasts and preferentially form bone matrix in those locations (55). Osteoblast precursors respond to changes in surface topography, whether the change is much larger than the cell itself, as occurs with osteoclastic activity, or very much smaller than the cell (56). Altered nanotopography induces osteoblast filopodia formation followed by cytoskeletal changes involving cell adhesion and differentiation. However, whether osteoblasts preferentially form matrix on disrupted bone because they truly "sense" a change in physical dimensions of the bone or because they detect a change in surface composition is unclear; both scenarios are plausible. However, it is unlikely that the existence of a resorbed space provides all the information required for osteoblasts to initiate and complete refilling of the space with no input from other cell types. If that were true, remodeling would always be balanced and bone mass constant even in the presence of alterations in intercellular signals.

\section{REVERSAL CELLS}

Another cell type that may respond to coupling factors are the reversal cells residing on the bone surface between the bone formation and resorption phases (10). These may provide both a physical and a temporal connection between the osteoclast and the osteoblast. They may respond to osteoclastderived coupling factors (57), and pass the necessary signals to the osteoblast precursors as they move onto the bone surface. Interrogating this possibility remains a challenge, since the reversal cells lack specific identifying features that can be targeted by genetic or pharmacological means.

\section{REMODELING CANOPY}

The remodeling canopy is another possible target for coupling factors (57). This anatomical structure consists of osteoblast-lineage cells that lift from the bone surface when osteoclastic resorption initiates the remodeling cycle (43). It has been suggested that the canopy is required for completion of the reversal phase, since biopsies from postmenopausal and glucocorticoid-induced osteoporotic patients exhibit incomplete canopies at sites of reversal phase arrest $(58,59)$. The canopy could also provide a controlled locale in which osteoblast-lineage cells, osteoclasts, and other contributing marrow cells, may exchange factors and influence precursors provided by the associated vasculature $(41,42)$. The bone remodeling canopy might serve as a way to keep local coupling factor concentrations sufficiently high to allow mesenchymal stem cell recruitment and to stimulate bone formation, or may limit the cellular contributors to the coupling processes. Defining 


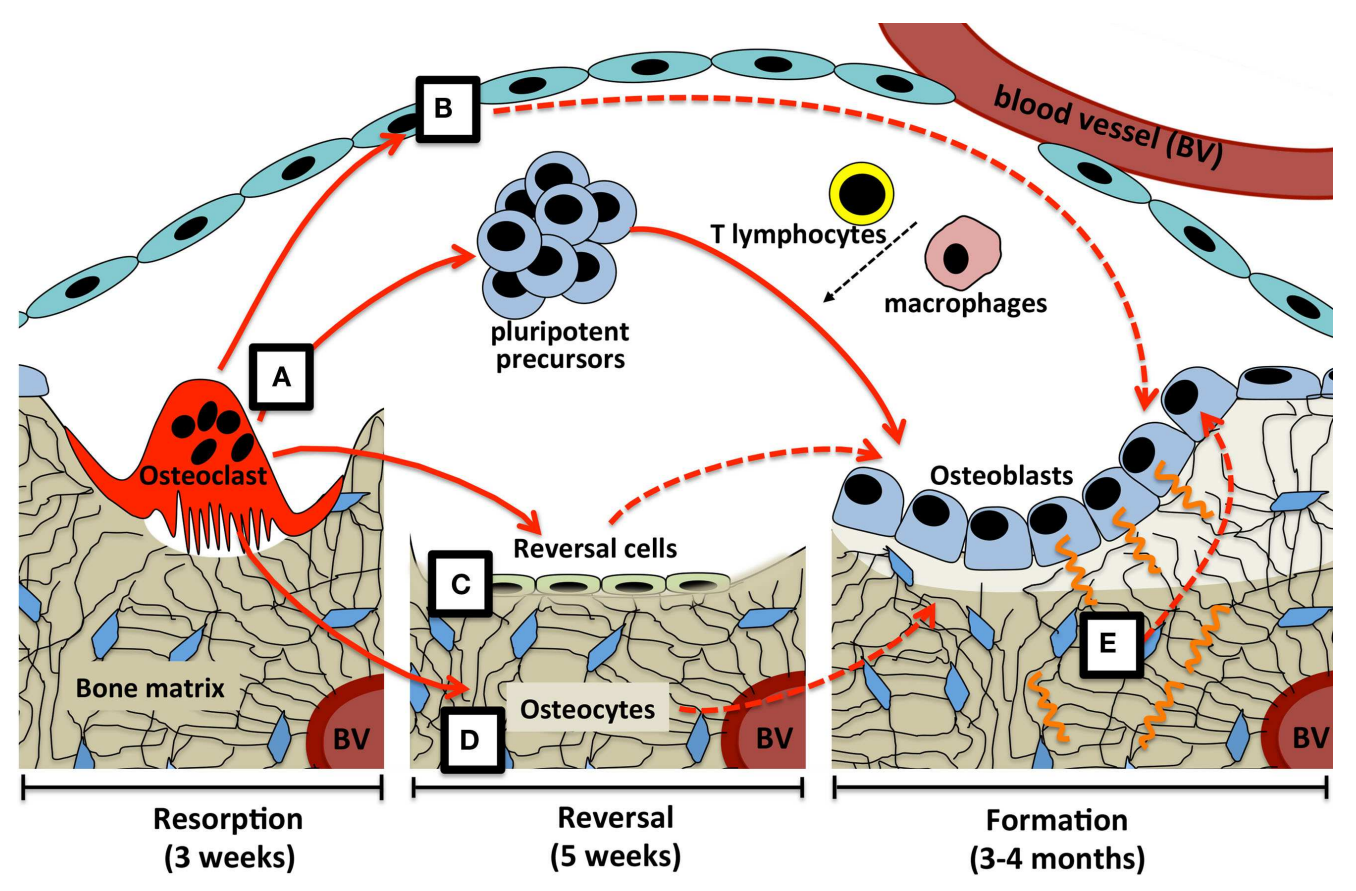

FIGURE 1 | Possible coupling mechanisms that overcome the time delay between bone resorption and formation. (A) Osteoclast-derived factors (either released from the matrix, secreted from the osteoclast, or expressed on the osteoclast cell membrane) initiate differentiation of very early osteoblast progenitors, with the level of osteoblast activity and numbers of differentiated cells being refined by other factors released by a range of cell types within the BMU. Osteoclast-derived factors may act directly on cells that would transmit further signals (dashed lines) to both osteoblast precursors and mature osteoblasts; these transmitting cells could include (B) osteoblast-lineage cells in the remodeling canopy, (C) reversal cells on the bone surface, and (D) osteocytes. Finally, (E) physical changes brought about by the osteoclast, including the resorptive pit itself, and mechanical strain detected by the osteocyte network, would provide signals required for initiation and completion of the correct level of matrix production by mature osteoblasts on the bone surface. Periods of time required for each step are based on adult human iliac crest biopsies. the canopy's contribution to the coupling process using genetically altered mouse models is limited because this anatomical structure has not been observed in the mouse, the model used most extensively for defining intercellular signaling pathways involved in bone remodeling.

\section{OSTEOCYTES}

Is there a role for the osteocyte in transmitting the messages from osteoclast to osteoblast in the BMU? Osteocytes are osteoblast-lineage cells trapped in the bone matrix during bone formation. They form an extensive interconnected network within a fluid-filled canalicular system (60), which may sense and respond to mechanical strain, as well as paracrine and endocrine signals (61). Osteocytes are present within the BMU throughout remodeling, and may therefore provide a system to transfer information from the resorbing osteoclast to bone surface osteoblasts. While few osteoclast-derived "coupling factors" have been shown to directly influence osteocytes, CT-1 reduces expression of sclerostin (52). CT-1 released by osteoclasts might therefore enter the lacunar-canalicular network, and act on those osteocytes closest to the resorptive site. When mature osteoblasts arrive on the bone surface, if sclerostin expression in the local area is still suppressed, this would allow bone formation to occur in this area. The factors that stimulate osteocytes to promote bone formation at resorbed sites may not be limited to CT-1. The mechanical disturbance caused by resorption itself may also "activate" osteocytes, and stimulate them to provide messages that promote bone formation on the same surface. One key question that remains is whether such a paracrine signaling mechanism could overcome the time delay between resorption and formation. For how long can osteocytes "retain" such information?

A mechanism that would not require a delayed communication system involving osteocytes is their detection and response to changes in microstrain that would occur during the remodeling process. Osteocytes would sense not only the increased strain resulting from weakening of the bone as resorption progresses (62) but would also detect when the strain is relieved as the bone is rebuilt by osteoblasts. Such a strain-based model for coupling was proposed some years ago (63) and now that our understanding of osteocyte signaling has improved, possible mediators are now coming to light. For example, sclerostin may mediate this process: sclerostin is significantly reduced by mechanical loading, and increased during unloading (64). Osteocytes may provide the final refining control to ensure that sufficient bone is formed by osteoblasts, generated in response to messages from osteoclasts either directly or via other cells within the BMU.

\section{CONCLUDING COMMENTS}

In conclusion, this suggests three mechanisms by which osteoclast-derived coupling signals may overcome the time delay 
between bone resorption and formation at the BMU (Figure 1). Osteoclast-derived factors (either released from the matrix, secreted from the osteoclast, or expressed on the cell membrane) initiate differentiation of very early osteoblast progenitors, with the level of osteoblast activity and numbers of differentiated cells being refined by other factors released by a range of cell types within the BMU. Second, osteoclast-derived factors may act directly on cells that would transmit further signals to both osteoblast precursors and mature osteoblasts; these transmitting cells could include reversal cells, osteoblast-lineage cells in the remodeling canopy, and osteocytes. Finally, physical changes brought about by the osteoclast would provide osteocytic signals required for initiation and completion of the correct level of matrix production by mature osteoblasts on the bone surface.

\section{REFERENCES}

1. Frost HM. Dynamics of bone remodeling. In: Frost HM, editor. Bone Biodynamics. Boston, MA: Little, Brown \& Co. (1964). p. 315-33.

2. Howard GA, Bottemiller BL, Turner RT, Rader JI, Baylink DJ. Parathyroid hormone stimulates bone formation and resorption in organ culture: evidence for a coupling mechanism. Proc Natl Acad Sci U S A (1981) 78:3204-8. doi:10.1073/pnas.78. 5.3204

3. Martin TJ, Sims NA. Osteoclast-derived activity in the coupling of bone formation to resorption. Trends Mol Med (2005) 11:76-81. doi:10.1016/j. molmed.2004.12.004

4. Sims NA, Gooi JH. Bone remodeling: multiple cellular interactions required for coupling of bone formation and resorption. Semin Cell Dev Biol (2008) 19:444-51. doi:10.1016/j.semcdb.2008.07. 016

5. Martin TJ, Gooi JH, Sims NA. Molecular mechanisms in coupling of bone formation to resorption. Crit Rev Eukaryot Gene Expr (2009) 19:73-88. doi:10.1615/CritRevEukarGeneExpr.v19.i1.40

6. Sims NA, Martin TJ. Coupling the activities of bone formation and resorption: a multitude of signals within the basic multicellular unit. Bonekey Rep (2014) 3:481. doi:10.1038/bonekey.2013.215

7. Sims NA, Quinn JM, Martin TJ. Coupling between immune and bone cells. In: Lorenzo JA, Choi Y, Horowitz MC, Takayanagi H, editors. Osteoimmunology: Interactions of the Immune and Skeletal Systems. 2nd ed. London: Academic Press (Forthcoming).

8. Eriksen EF, Melsen F, Mosekilde L. Reconstruction of the resorptive site in iliac trabecular bone: a kinetic model for bone resorption in 20 normal individuals. Metab Bone Dis Relat Res (1984) 5:235-42. doi:10.1016/0221-8747(84)90065-1

9. Eriksen EF, Gundersen HJ, Melsen F, Mosekilde L. Reconstruction of the formative site in iliac trabecular bone in 20 normal individuals employing a kinetic model for matrix and mineral apposition. Metab Bone Dis Relat Res (1984) 5:243-52. doi:10. 1016/0221-8747(84)90065-1

10. Tran Van P, Vignery A, Baron R. An electronmicroscopic study of the bone-remodeling sequence in the rat. Cell Tissue Res (1982) 225:283-92. doi:10.1007/BF00214682

11. Vignery A, Baron R. Dynamic histomorphometry of alveolar bone remodeling in the adult rat. Anat Rec (1980) 196:191-200. doi:10.1002/ar. 1091960210

12. Jensen PR, Andersen TL, Pennypacker BL, Duong LT, Delaisse JM. The bone resorption inhibitors odanacatib and alendronate affect postosteoclastic events differently in ovariectomized rabbits. Calcif Tissue Int (2014) 94:212-22. doi:10. 1007/s00223-013-9800-0

13. Parfitt AM. The coupling of bone formation to bone resorption: a critical analysis of the concept and of its relevance to the pathogenesis of osteoporosis. Metab Bone Dis Relat Res (1982) 4:1-6. doi:10.1016/0221-8747(82)90002-9

14. Andersen TL, Abdelgawad ME, Kristensen HB, Hauge EM, Rolighed L, Bollerslev J, et al. Understanding coupling between bone resorption and formation: are reversal cells the missing link? Am J Pathol (2013) 183:235-46. doi:10.1016/j.ajpath. 2013.03.006

15. Cochrane JH. Presidential address: discount rates. J Finance (2011) 66:1047-108. doi:10.1111/j.15406261.2011.01671.x

16. Hsu J, Kalesnik V. Finding smart beta in the factor zoo. Fundamentals (2014).

17. Hanamura H, Higuchi $Y$, Nakagawa M, Iwata $H$, Nogami H, Urist MR. Solubilized bone morphogenetic protein (BMP) from mouse osteosarcoma and rat demineralized bone matrix. Clin Orthop Relat Res (1980) 148:281-90.

18. Centrella M, Canalis E. Local regulators of skeletal growth: a perspective. Endocr Rev (1985) 6:544-51. doi:10.1210/edrv-6-4-544

19. Pfeilschifter J, Mundy GR. Modulation of type beta transforming growth factor activity in bone cultures by osteotropic hormones. Proc Natl Acad Sci U S A (1987) 84:2024-8. doi:10.1073/pnas.84.7. 2024

20. Oreffo RO, Mundy GR, Seyedin SM, Bonewald LF. Activation of the bone-derived latent TGF beta complex by isolated osteoclasts. Biochem Biophys Res Commun (1989) 158:817-23. doi:10.1016/ 0006-291X(89)92795-2

21. Hock JM, Canalis E, Centrella M. Transforming growth factor-beta stimulates bone matrix apposition and bone cell replication in cultured fetal rat calvariae. Endocrinology (1990) 126:421-6. doi:10. 1210/endo-126-1-421

22. Campbell PG, Novak JF, Yanosick TB, McMaster $\mathrm{JH}$. Involvement of the plasmin system in dissociation of the insulin-like growth factor-binding protein complex. Endocrinology (1992) 130:1401-12. doi:10.1210/en.130.3.1401

23. Yee JA, Yan L, Dominguez JC, Allan EH, Martin TJ. Plasminogen-dependent activation of latent transforming growth factor beta (TGF beta) by growing cultures of osteoblast-like cells. J Cell Physiol (1993) 157:528-34. doi:10.1002/jcp.1041570312

24. Dallas SL, Rosser JL, Mundy GR, Bonewald LF. Proteolysis of latent transforming growth factor-beta
(TGF-beta)-binding protein-1 by osteoclasts. A cellular mechanism for release of TGF-beta from bone matrix. J Biol Chem (2002) 277:21352-60. doi:10.1074/jbc.M111663200

25. Hock JM, Canalis E. Platelet-derived growth factor enhances bone cell replication, but not differentiated function of osteoblasts. Endocrinology (1994) 134:1423-8. doi:10.1210/endo.134.3.8119182

26. Fiedler J, Roderer G, Gunther KP, Brenner RE. BMP-2, BMP-4, and PDGF-bb stimulate chemotactic migration of primary human mesenchymal progenitor cells. J Cell Biochem (2002) 87:305-12. doi:10.1002/jcb.10309

27. Xian L, Wu X, Pang L, Lou M, Rosen CJ, Qiu $\mathrm{T}$, et al. Matrix IGF-1 maintains bone mass by activation of mTOR in mesenchymal stem cells. Nat Med (2012) 18:1095-101. doi:10.1038/nm. 2793

28. Sanchez-Fernandez MA, Gallois A, Riedl T, Jurdic P, Hoflack B. Osteoclasts control osteoblast chemotaxis via PDGF-BB/PDGF receptor beta signaling. PLoS One (2008) 3:e3537. doi:10.1371/ journal.pone.0003537

29. Tang Y, Wu X, Lei W, Pang L, Wan C, Shi Z, et al. TGF-betal-induced migration of bone mesenchymal stem cells couples bone resorption with formation. Nat Med (2009) 15:757-65. doi:10.1038/ nm.1979

30. Kreja L, Brenner RE, Tautzenberger A, Liedert A, Friemert B, Ehrnthaller C, et al. Non-resorbing osteoclasts induce migration and osteogenic differentiation of mesenchymal stem cells. JCell Biochem (2010) 109:347-55. doi:10.1002/jcb.22406

31. Rickard DJ, Sullivan TA, Shenker BJ, Leboy PS, Kazhdan I. Induction of rapid osteoblast differentiation in rat bone marrow stromal cell cultures by dexamethasone and BMP-2. Dev Biol (1994) 161:218-28. doi:10.1006/dbio.1994.1022

32. Mitlak BH, Finkelman RD, Hill EL, Li J, Martin B, Smith T, et al. The effect of systemically administered PDGF-BB on the rodent skeleton. J Bone Miner Res (1996) 11:238-47. doi:10.1002/ jbmr.5650110213

33. Walker EC, McGregor NE, Poulton IJ, Pompolo S, Allan EH, Quinn JM, et al. Cardiotrophin-1 is an osteoclast-derived stimulus of bone formation required for normal bone remodeling. J Bone Miner Res (2008) 23:2025-32. doi:10.1359/jbmr. 080706

34. Pederson L, Ruan M, Westendorf JJ, Khosla S, Oursler MJ. Regulation of bone formation by osteoclasts involves Wnt/BMP signaling and the chemokine sphingosine-1-phosphate. Proc Natl Acad Sci U S A (2008) 105:20764-9. doi:10.1073/ pnas.0805133106

35. Takeshita S, Fumoto T, Matsuoka K, Park KA, Aburatani H, Kato S, et al. Osteoclast-secreted CTHRC1 in the coupling of bone resorption to formation. J Clin Invest (2013) 123(9):3914-24. doi:10.1172/JCI69493

36. Matsuoka K, Park KA, Ito M, Ikeda K, Takeshita S. Osteoclast-derived complement component 3a stimulates osteoblast differentiation. J Bone Miner Res (2014) 29:1522-30. doi:10.1002/jbmr. 2187

37. Karsdal MA, Neutzsky-Wulff AV, Dziegiel MH, Christiansen C, Henriksen K. Osteoclasts secrete non-bone derived signals that induce bone 
formation. Biochem Biophys Res Commun (2008) 366:483-8. doi:10.1016/j.bbrc.2007.11.168

38. Sims NA, Ng KW. Implications of osteoblastosteoclast interactions in the management of osteoporosis by antiresorptive agents denosumab and odanacatib. Curr Osteoporos Rep (2014) 12:98-106. doi:10.1007/s11914-014-0196-1

39. Zhao C, Irie N, Takada Y, Shimoda K, Miyamoto T, Nishiwaki T, et al. Bidirectional ephrinB2EphB4 signaling controls bone homeostasis. Cell Metab (2006) 4:111-21. doi:10.1016/j.cmet.2006. 05.012

40. Negishi-Koga T, Shinohara M, Komatsu N, Bito H, Kodama T, Friedel RH, et al. Suppression of bone formation by osteoclastic expression of semaphorin 4D. Nat Med (2011) 17:1473-80. doi:10. 1038/nm.2489

41. Kristensen HB, Andersen TL, Marcussen N, Rolighed L, Delaisse JM. Increased presence of capillaries next to remodeling sites in adult human cancellous bone. J Bone Miner Res (2013) 28:574-85. doi:10.1002/jbmr.1760

42. Kristensen HB, Andersen TL, Marcussen N, Rolighed L, Delaisse JM. Osteoblast recruitment routes in human cancellous bone remodeling. Am J Pathol (2014) 184:778-89. doi:10.1016/j.ajpath. 2013.11.022

43. Andersen TL, Sondergaard TE, Skorzynska KE, Dagnaes-Hansen F, Plesner TL, Hauge EM, et al. A physical mechanism for coupling bone resorption and formation in adult human bone. Am J Pathol (2009) 174:239-47. doi:10.2353/ajpath. 2009.080627

44. Chen W, Jin W, Wahl SM. Engagement of cytotoxic T lymphocyte-associated antigen 4 (CTLA4) induces transforming growth factor beta (TGFbeta) production by murine CD4(+) T cells. J Exp Med (1998) 188:1849-57. doi:10.1084/jem.188.10. 1849

45. Wang X, Kumanogoh A, Watanabe C, Shi W, Yoshida K, Kikutani H. Functional soluble CD100/Sema4D released from activated lymphocytes: possible role in normal and pathologic immune responses. Blood (2001) 97:3498-504. doi:10.1182/blood.V97.11.3498

46. Terauchi M, Li JY, Bedi B, Baek KH, Tawfeek H, Galley S, et al. T lymphocytes amplify the anabolic activity of parathyroid hormone through Wnt10b signaling. Cell Metab (2009) 10:229-40. doi:10.1016/j.cmet.2009.07.010

47. Fadok VA, Bratton DL, Konowal A, Freed PW, Westcott JY, Henson PM. Macrophages that have ingested apoptotic cells in vitro inhibit proinflammatory cytokine production through autocrine/paracrine mechanisms involving
TGF-beta, PGE2, and PAF. J Clin Invest (1998) 101:890-8. doi:10.1172/JCI1112

48. Champagne CM, Takebe J, Offenbacher S, Cooper LF. Macrophage cell lines produce osteoinductive signals that include bone morphogenetic protein-2. Bone (2002) 30:26-31. doi:10.1016/ S8756-3282(01)00638-X

49. Daniel TO, Fen Z. Distinct pathways mediate transcriptional regulation of platelet-derived growth factor B/c-sis expression. J Biol Chem (1988) 263:19815-20.

50. Scariano JK, Emery-Cohen AJ, Pickett GG, Morgan $\mathrm{M}$, Simons PC, Alba F. Estrogen receptors alpha (ESR1) and beta (ESR2) are expressed in circulating human lymphocytes. J Recept Signal Transduct Res (2008) 28:285-93. doi:10.1080/ 10799890802084614

51. Allan EH, Ho PW, Umezawa A, Hata J, Makishima F, Gillespie MT, et al. Differentiation potential of a mouse bone marrow stromal cell line. J Cell Biochem (2003) 90:158-69. doi:10.1002/jcb. 10614

52. Walker EC, McGregor NE, Poulton IJ, Solano M, Pompolo S, Fernandes TJ, et al. Oncostatin M promotes bone formation independently of resorption when signaling through leukemia inhibitory factor receptor in mice. J Clin Invest (2010) 120:582-92. doi:10.1172/JCI40568

53. Woo SM, Rosser J, Dusevich V, Kalajzic I, Bonewald LF. Cell line IDG-SW3 replicates osteoblast-tolate-osteocyte differentiation in vitro and accelerates bone formation in vivo. J Bone Miner Res (2011) 26:2634-46. doi:10.1002/jbmr.465

54. Matthews BG, Grcevic D, Wang L, Hagiwara Y, Roguljic H, Joshi P, et al. Analysis of alphaSMAlabeled progenitor cell commitment identifies notch signaling as an important pathway in fracture healing. J Bone Miner Res (2014) 29:1283-94. doi:10.1002/jbmr.2140

55. Gray C, Boyde A, Jones SJ. Topographically induced bone formation in vitro: implications for bone implants and bone grafts. Bone (1996) 18:115-23. doi:10.1016/8756-3282(95)00456-4

56. Dalby MJ, McCloy D, Robertson M, Wilkinson CD, Oreffo RO. Osteoprogenitor response to defined topographies with nanoscale depths. Biomaterials (2006) 27:1306-15. doi:10.1016/j.biomaterials. 2005.08.028

57. Delaisse JM. The reversal phase of the boneremodeling cycle: cellular prerequisites for coupling resorption and formation. Bonekey Rep (2014) 3:561. doi:10.1038/bonekey.2014.56

58. Andersen TL, Hauge EM, Rolighed L, Bollerslev J, Kjærsgaard-Andersen P, Delaisse JM. Correlation between absence of bone remodeling compartment canopies, reversal phase arrest, and deficient bone formation in post-menopausal osteoporosis. Am J Pathol (2014) 184:1142-51. doi:10.1016/j.ajpath.2013.12.005

59. Jensen PR, Andersen TL, Hauge E-M, Bollerslev J, Delaissé J-M. A joined role of canopy and reversal cells in bone remodeling - lessons from glucocorticoid-induced osteoporosis. Bone (2015) 73:16-23. doi:10.1016/j.bone.2014.12.004

60. Buenzli PR, Sims NA. Quantifying the extent of the human osteocyte network. Bone (2015) 75:144-50. doi:10.1016/j.bone.2015.02.016

61. Schaffler MB, Cheung WY, Majeska R, Kennedy O. Osteocytes: master orchestrators of bone. Calcif Tissue Int (2014) 94:5-24. doi:10.1007/s00223013-9790-y

62. McNamara LM, Van Der Linden JC, Weinans $\mathrm{H}$, Prendergast PJ. Stress-concentrating effect of resorption lacunae in trabecular bone. J Biomech (2006) 39:734-41. doi:10.1016/j.jbiomech. 2004.12.027

63. Rodan GA. Mechanical loading, estrogen deficiency, and the coupling of bone formation to bone resorption. J Bone Miner Res (1991) 6:527-30. doi:10.1002/jbmr.5650060602

64. Robling AG, Niziolek PJ, Baldridge LA, Condon KW, Allen MR, Alam I. et al. Mechanical stimulation of bone in vivo reduces osteocyte expression of Sost/sclerostin. J Biol Chem (2008) 283:5866-75. doi:10.1074/jbc.M705092200

Conflict of Interest Statement: The authors declare that the research was conducted in the absence of any commercial or financial relationships that could be construed as a potential conflict of interest.

Received: 16 February 2015; paper pending published: 04 March 2015; accepted: 10 March 2015; published online: 24 March 2015

Citation: Sims NA and Martin TJ (2015) Coupling signals between the osteoclast and osteoblast: how are messages transmitted between these temporary visitors to the bone surface? Front. Endocrinol. 6:41. doi: 10.3389/fendo.2015.00041

This article was submitted to Bone Research, a section of the journal Frontiers in Endocrinology.

Copyright (c) 2015 Sims and Martin. This is an openaccess article distributed under the terms of the Creative Commons Attribution License (CC BY). The use, distribution or reproduction in other forums is permitted, provided the original author(s) or licensor are credited and that the original publication in this journal is cited, in accordance with accepted academic practice. No use, distribution or reproduction is permitted which does not comply with these terms. 